\title{
EL SENADO ARGENTINO: ACTUALIDAD Y PERSPECTIVAS DE FUTURO
}

\author{
GERARDO PISARELLO* \\ Profesor Lector de Derecho Constitucional \\ Universidad de Barcelona
}
SUMARIO
I. De los orígenes a la reforma constitucio- nal de 1994.
II. Composición, estructura y funciones del Senado argentino.
III. El Senado en las entidades federadas.
IV. El Senado argentino en el sistema consti- tucional y sus perspectivas de futuro.

\section{DE LOS ORÍGENES A LA REFORMA CONSTITUCIONAL DE 1994}

El debate sobre la descentralización política y sobre el papel del Senado en las instituciones argentinas tiene como referencia obligada la Constitución federal de 1853. Tras la primera reforma de 1860 y la última, de 1994, éste es el texto vigente todavía hoy. Sin embargo, la función de la Cámara Alta no puede explicarse al margen de un proceso histórico que arranca en el momento mismo de la separación del imperio español y se proyecta hasta la actualidad.

Desde la revolución criolla que en 1810 se convierte en disparador del proceso de independencia política de España, puede apreciarse un conflicto abierto entre dos sectores, uno de tendencias más bien liberales y centralistas, otro de tendencias más bien conservadoras y federalizantes ${ }^{1}$. Se da así una paradoja que marca desde sus inicios la práctica constitucional argentina y que la di-

* Este trabajo se enmarca en el Proyecto de Investigación del Ministerio de Ciencia y Tecnología B-J2003-06043.

1 Vid., entre otros, J. C. CHIARAMONTE, "El federalismo argentino en la primera mitad del siglo XIX", en M. Carmignani (coord.), Federalismos latinoamericanos. México/ Brasil/ Argentina, Fondo de Cultura Económica, México, 1993, pp. 81 y ss. 
ferencia de otras experiencias latinoamericanas. Los sectores liberales, afincados principalmente en Buenos Aires, son reacios al federalismo y propugnan una cierta restricción de la representación popular en nombre de los ideales ilustrados. Los grupos conservadores, con frecuencia apoyados en importantes sectores populares del interior del país, vinculan la defensa del federalismo al mantenimiento de privilegios corporativos y de una ideología hispánica autoritaria y anti-liberal ${ }^{2}$.

De ese modo, la construcción del Estado nacional aparece atravesada, de un lado, por el sometimiento de los diferentes pueblos indígenas que habitan el territorio, y de otro, por las feroces luchas y compromisos entre Buenos Aires, sus aliados, y el resto de provincias, así como entre distintos bandos de "unitarios" $\mathrm{y}$ "federales". Tras un largo enfrentamiento, precisamente, entre tendencias unitarias y centralistas, en 1852 se celebra el llamado Pacto de San Nicolás, que sirve de base a la Constitución de 1853. Su aprobación cuenta con la representación de las 13 provincias "originarias" —Catamarca, Córdoba, Corrientes, Entre Ríos, Jujuy, La Rioja, Mendoza, Salta, San Juan, San Luis, Santa Fe, Santiago del Estero, Tucumán- y con la notable ausencia de Buenos Aires. Al igual que en otros ordenamientos de América Latina, la Constitución de Estados Unidos de 1787 ejerce una influencia clave en la configuración del nuevo texto constitucional. Sin embargo, también se establecen algunos caracteres diferenciales y autóctonos ${ }^{3}$.

Según el artículo 36 de la Constitución de 1853, el Poder Legislativo se integra por un "Congreso" compuesto por dos "Cámaras": una de "diputados de la Nación" y otra de "senadores de las provincias y de la Capital". En el capítulo I, el Senado se consagra como la Cámara federal por antonomasia. Al igual que ocurre con el Senado de los Estados Unidos, el artículo 46 establece una composición paritaria de dicho órgano, con 2 senadores por cada una de las 13 provincias y 2 por la Capital federal.

Una reforma en 1860 cambia el nombre de la Constitución, que pasa a denominarse "de la Nación Argentina" ${ }^{4}$. Aunque la expresión "Confederación" es

2 Lo cual no quiere decir que no se planteen otras opciones que apuesten por una combinación entre federalismo, autodeterminación y libertades políticas, civiles y sociales. Ese será, por ejemplo, el núcleo del pensamiento y de la práctica de José Gervasio de Artigas, Manuel Dorrego o Leandro Alem. Vid., al respecto, R. GARGARELLA, Los fundamentos legales de la desigualdad. El constitucionalismo en América (1776-1980), Siglo XXI, Madrid, 2005, pp. 52 y ss.

3 El pensamiento de Juan Bautista Alberdi, precursor del Derecho público argentino y autor de las Bases y puntos de partida para la Organización Política de la República Argentina, es determinante. Sus ideas contribuyen a adaptar el "modelo" de los Estados Unidos y se traducen en la consagración de una Federación más centralizada, basada en un sistema presidencial fuerte y un bicameralismo relativamente equilibrado.

4 Parte de la doctrina, de hecho, sostiene que debe considerarse Constitución originaria a la de "1853-1860", ya que es el producto de la simbiosis entre dos momentos y dos sujetos constituyentes diversos. En la de 1853, se expresa un sujeto constituyente parcial -los representantes de los pueblos de 13 provincias- que se completa con en 1860, cuando concurren los representantes de Buenos Aires. La Constitución todavía vigente, en realidad, se basa sobre todo en la primera, pero con las importantes adiciones efectuadas por la segunda. 
reemplazada por la expresión "Nación", las provincias ganan autonomía y se amplían sus competencias. A pesar de que la Constitución de 1853-1860 mantiene algunos períodos de vigencia formal, sus infracciones, quebrantamientos o adulteraciones son frecuentes. En 1880 se completa la federalización de Buenos Aires. A partir de 1882, el número de senadores se eleva de 28 a 30. Desaparecen los ejércitos particulares al servicio de una provincia, así como la existencia de regiones o ciudades con capacidad para disputar el monopolio de la coacción al gobierno federal.

Hacia el final de siglo, se instala un ciclo liberal en lo que económico que favorece una particular combinación de "centralismo autoritario" $\mathrm{y}$ "federalismo ilustrado" 5 . En ese "orden conservador", cuyas características centrales son la exclusión social y el fraude electoral, el Senado pasa a ser el ámbito natural de vínculo entre el gobierno federal y los gobernadores, dentro de un marco presidencialista que favorece a las provincias más ricas y a las clases sociales más acomodadas ${ }^{6}$. En los 36 años que median entre 1880 y 1916, se producen 40 intervenciones en las provincias: 25 por ley y 15 mediante decreto del Poder ejecutivo ${ }^{7}$.

En 1912, una reforma política introduce el sufragio universal masculino. Se abre así un nuevo período de regeneracionismo democrático que se traduce en el respeto de ciertas libertades políticas. Las declaraciones de Estado de sitio disminuyen claramente — sólo se producen 2 entre 1916 y 1930 - pero no las intervenciones federales, que intentan quebrar, una y otra vez, la férrea resistencia de las oligarquías provinciales y su poder en el Senado. En 1930, un golpe de Estado impulsado por grupos fascistas y conservadores produce la primera fractura grave en el orden institucional establecido en 1860. A partir de entonces, y hasta 1983, se suceden de manera interrumpida 6 golpes de Estados en la historia argentina. Como consecuencia de ello, la Cámara de Diputados y el Senado permanecen clausurados durante un total de más de 23 años. La concentración de poder que suponen los gobiernos militares - reforzamiento del presidencialismo, disolución del Congreso, nombramiento de gobernadores militares de las provincias, concentración de poder económico- deteriora todavía más una práctica federal de por sí vulnerable ${ }^{8}$.

5 Vid., entre otros, N. BOTANA, "El federalismo liberal en Argentina: 1852-1930", en M. Carmagnani (coord.), Federalismos latinoamericanos, op. cit., pp. 224 y ss.

6 En efecto, el mandato renovable de 9 años de los senadores y su origen electoral indirecto — son designados por las legislaturas provinciales- convierten al Senado en un ámbito estable de comunicación entre el gobierno federal y las provincias. Así, es frecuente observar itinerarios de ida y vuelta de los senadores que obtienen en su provincia el beneficio de la reelección.

7 En el caso "Cullen c. Llerena", de 1983, la Corte Suprema deja sentado que toda la materia de la intervención federal en las provincias es una "cuestión política" no susceptible de ser revisada judicialmente.

8 En septiembre de 1930, la Corte Suprema dicta una Acordada que consiente tal situación. En el caso "Malmonge Nobreda", de 1933, la Corte es más explícita en las facultades reconocidas al gobierno de facto. Dichas facultades incluirían las del Poder ejecutivo y sólo en caso de necesidad vital las del Legislativo, mediante decretos leyes que expirarían cuando cesara la autoridad de facto. Sobre sus consecuencias para la fragilidad futura del sistema liberal-democrático, Vid., C. S. NINO, Fundamentos de derecho constitucional, Astrea, Buenos Aires, 2002. 
Tras una década caracterizada por la represión política y el fraude electoral, en 1946 accede al poder Juan D. Perón. La expresión más amplia de la concepción institucional y social del peronismo es la Constitución de 19499. Inscrita en el ciclo del constitucionalismo populista abierto en América Latina tras la segunda posguerra, el texto de 1949 combina una fuerte impronta social, que favorece el paso de un federalismo "dual" o "competitivo" a un federalismo de tipo "Cooperativo", con un robustecimiento del papel del Estado y del propio Poder ejecutivo ${ }^{10}$.

En 1955, un nuevo golpe de Estado militar derroca al gobierno peronista. Por primera vez, los miembros de la Corte Suprema de Justicia son depuestos. Por medio de decretos leyes, un gobierno provisional se atribuye las competencias legislativas encomendadas a la Cámara de Diputados y al Senado. En 1957 tiene lugar una nueva reforma: la Constitución de 1853-1860 recupera su vigencia formal.

En 1976 estalla otro golpe de Estado militar. El período dictatorial que se extiende hasta 1983 supera todos los anteriores en su carácter totalitario y en la vulneración de derechos fundamentales que produce. Se disuelven las Cámaras, una Junta de Comandantes asume facultades ejecutivas y legislativas casi absolutas y se pone en marcha un programa de restricción del gasto social que tiene un fuerte impacto en la situación económica de la mayoría de las provincias.

En 1983, tras la caída de la dictadura, se convocan elecciones democráticas y se abre un nuevo período institucional. Raúl Alfonsín, de la Unión Cívica Radical, es elegido presidente. La Constitución de 1853, con sus diferentes reformas, recupera su vigencia. Por primera vez en décadas, no se produce durante su mandato ninguna intervención federal a las provincias. Un "Consejo para la Consolidación de la Democracia", convocado por el gobierno e integrado por expertos, representantes de los partidos y de la "sociedad civil", presenta un proyecto de reforma constitucional que incluye enmiendas importantes al papel del Senado.

En 1989, tras una fuerte crisis política y económica, asume la presidencia Carlos Menem, del Partido Justicialista. En 1992, el número de senadores aumenta a 48, como producto de la incorporación de la nueva provincia de Tierra del Fuego, Antártida e Islas del Atlántico Sur. En 1994, Alfonsín y Menem protagonizan el Pacto de Olivos, con el objetivo de impulsar una reforma constitucional. El objetivo principal de la reforma es facilitar la reelección de Menem

9 Esta reforma, impulsada por la intención de Perón de obtener la posibilidad de su reelección, es impugnada por los demás partidos de oposición, por no cumplirse escrupulosamente con los requisitos establecidos en el artículo 30 de la Constitución de 1853.

10 En su artículo 47, la Constitución de 1949 establece que los 2 senadores provinciales y los 2 de la Capital serán elegidos "directamente por el pueblo". El artículo 49, por su parte, reduce el mandato de los senadores a 6 años y estipula que el Senado se renovará por mitad cada tres años. En 1947 se aprueba la ley de voto femenino. A partir de 1952, las mujeres se incorporan al Congreso (23 diputadas y 6 senadoras). Durante la vigencia de la reforma de 1949, se crean también nuevas provincias: Chaco y La Pampa. El número total de senadores pasa a 34. 
y, de manera paralela, asegurar la designación de dos nuevos magistrados de la Corte Suprema, tras hacer renunciar a otros dos. El acuerdo, sin embargo, comporta una serie de enmiendas de de alcance más amplio, que influyen en la fisonomía "federal" del texto constitucional. En lo que se refiere al papel del Senado, la reforma introduce tres cambios sustanciales, todavía vigentes ${ }^{11}$.

a) En primer lugar, el nuevo artículo 54 del texto reformado aumenta el número de senadores a 3 por cada una de las 23 provincias, más 3 por la "ciudad autónoma" de Buenos Aires. Asimismo, establece su elección directa y conjunta, correspondiendo 2 escaños al partido político que obtenga el mayor número de votos, y el restante a la primera "minoría"

b) En segundo término, el artículo 56 reduce el mandato de los senadores a 6 años, mantiene la posibilidad de su reelección indefinida y dispone la renovación del Senado a razón de una tercera parte de los distritos electorales cada 2 años.

c) Finalmente, convierte al Senado en Cámara de origen para la tramitación de dos leyes de importancia central: la ley-convenio de coparticipación impositiva (artículo 75.2) y las leyes sobre "crecimiento armónico de la Nación y doblamiento de su territorio y promoción de políticas diferenciadas que tiendan a equilibrar el desigual desarrollo relativo de provincias y regiones" (artículo 75.19).

Como producto de la reforma de 1994, el número de senadores se eleva a 72, composición que permanece todavía hoy. En el año 2000, durante el gobierno de Fernando de la Rúa, algunos miembros del Senado pertenecientes a los dos partidos mayoritarios - la Unión Cívica Radical y el peronista Partido Justicialista - son acusados de soborno como contrapartida a la aprobación de una ley de reforma laboral. Este hecho, sumado a otras desavenencias con el Presidente de la Nación, desemboca en la renuncia del Vicepresidente de la Nación, Carlos Álvarez. Tras la fuerte crisis social e institucional de diciembre de 2001, las declaraciones de un "arrepentido" - por entonces Secretario Parlamentario del Senado- reabre en 2003 el escándalo por los sobornos. En un clima de grave deterioro económico y social, una larga sombra de sospecha pública se cierne sobre el papel institucional de la Cámara Alta. La desconfianza perdura todavía en la actualidad ${ }^{13}$.

11 Vid., entre otros, AA.VV., La Reforma Constitucional argentina 1994, Asocación Argentina de Derecho Constitucional, Buenos Aires, 1994; A. HERNÁNDEZ, "La ordenación de las instituciones y los poderes en los Estados compuestos", en Enric Argullol (director), Federalismo y autonomía, Ariel, Barcelona, 2004.

12 La creación del "tercer senador", ya establecida mientras estuvo vigente el Estatuto Fundamental de 1972, fue una de las condiciones principales que Alfonsín exigió a Menem en el Pacto de Olivos, a cambio de suprimir la prohibición de la reelección presidencial.

13 También en 2003, la imagen de los senadores se ve afectada de manera dramática cuando la Cámara decide no expulsar al senador Luis Barrionuevo, del Partido Justicialista, tras unos graves incidentes que motivan la suspensión de las elecciones en la provincia de Catamarca. Vid., entre otros, J. GENTILE, "El Senado: ¿es una Cámara federal?", en Walter F. Carnota (ed.), Derecho federal. Sus implicancias prácticas, Editorial Grün, 2005. 


\section{COMPOSICIÓN, ESTRUCTURA Y FUNCIONAMIENTO DEL SENADO ARGENTINO}

La regulación constitucional del Senado argentino se encuentra recogida en la Sección I del Título I de la Parte II de la Constitución, referida al Poder Legislativo ${ }^{14}$. Más allá de la regulación constitucional, cada Cámara dispone de su propio reglamento (con base en el artículo 66 de la Constitución). Aunque nada impide la aprobación de un reglamento del Congreso, actualmente existen dos diferenciados. El Reglamento del Senado (RS, de aquí en adelante), aprobado en 1861, ha sido objeto de numerosas reformas. Las últimas dos entraron en vigor en el año 2003.

Para el constituyente de 1853 , como se ha visto, resultaba clara la diferente legitimidad de origen de diputados y senadores. En el imaginario de los "padres fundadores", los primeros representan a "la Nación" y la Cámara que los reúne se percibe como un órgano más innovador pero también más expuesto a las "presiones populares". Los senadores, en cambio, representan a las provincias y a la capital, y la Cámara que los aglutina es percibida, al igual que en la tradición norteamericana, como un reducido órgano de "notables", con ritmos más lentos, capaz de actuar como contrapeso a la Cámara de diputados.

Tras la reforma de 1994, el Senado se compone de 72 miembros, frente a los 256 que integran el Congreso de los Diputados. El nuevo artículo 54 de la Constitución, en efecto, instituye la elección directa y conjunta de 3 senadores por cada provincia y 3 por la ciudad de Buenos Aires ${ }^{15}$. De los 3 escaños, 2 se atribuyen al partido político que haya obtenido más votos y el restante al que le sigue. El artículo 56, por su parte, reduce el mandato de los senadores a 6 años y ordena la renovación parcial del cuerpo, por tercios, cada 2.

Durante la Convención constituyente, algunos convencionales argumentaron que el tercer senador por la minoría suponía una lesión al federalismo, puesto que favorecía la partitocracia y asimilaba al Senado a la Cámara de Di-

14 Dicha Sección I consta de siete capítulos. El Capítulo I — artículos 45 a 53- se refiere a la Cámara de Diputados "de la Nación". El Capítulo II —artículos 54-62- establece los rasgos generales del Senado "de las provincias y de la ciudad de Buenos Aires". El Capítulo III —artículos 63 a 74 - regula las disposiciones comunes a ambas Cámaras del Congreso, incluido el estatuto de diputados y senadores. El Capítulo IV — artículos 75 y 76 - especifica las atribuciones del Congreso, reconociendo al Senado un amplio papel de colegislador así como otras funciones constitucionales específicas. El Capítulo V —artículos 77 a 84- establece el procedimiento de formación y sanción de las leyes. Finalmente, los Capítulos VI y VII — artículos 85 y 86 respectivamente - configuran la Auditoría de la Nación y la Defensoría del Pueblo como órganos de control externo de la administración pública, auxiliares del Congreso.

15 La elección de senadores por la Ciudad de Buenos Aires se explica por el nuevo estatus autonómico que se le reconoce en el artículo 129 de la Constitución. Por la misma razón se suprime la elección de senadores por la Capital, aunque a diferencia de los representantes de la Cámara Baja no se prevé que sucedería en caso de traslado de la Capital fuera de la Ciudad de Buenos Aires. 
putados. Desde posiciones opuestas, se argumentó que la nueva figura reconocía el peso legítimo de los partidos y mejoraría la representatividad y el pluralismo del órgano ${ }^{16}$. Una cláusula transitoria —la cuarta- reguló complejamente las renovaciones de 1995 y 1998. La cláusula transitoria quinta, a su vez, difirió la aplicación de la elección directa para 2001, año en que tendría lugar la renovación total del cuerpo. Asimismo, ordenó que una vez constituida la cámara después de esta última elección, se procediera a sortear los senadores que saldrán en el primero y segundo bienio. Esta renovación por bienios en los años impares unificaría las elecciones de senadores y diputados y bienio de por medio permitiría también la coincidencia con las presidenciales.

La cláusula transitoria cuarta estableció además la elección de senadores suplentes, que asumirían "en los casos del artículo 62". Este precepto constitucional, a su vez, estipula que "cuando vacase alguna plaza de senador por muerte, renuncia u otra causa, el Gobierno a que corresponda la vacante hace proceder de inmediato a la elección de un nuevo miembro" ${ }^{17}$. Desde 1994 hasta el 10 de diciembre de 2001, los 3 senadores y sus suplentes fueron elegidos, dos por la primera mayoría y uno por la segunda, por las legislaturas de las diferentes provincias y por un colegio electoral en la Ciudad autónoma de Buenos Aires.

A partir de las elecciones de 2001, se aplica lo dispuesto por el Decreto 1246 de 2000, reglamentario de la ley 24.012, según el cual los dos candidatos a senadores titulares deben pertenecer a distinto sexo, igual que los suplentes. Como consecuencia, se introduce un "cupo femenino" también para las lista de senadores.

Como recuerda el artículo 64 de la Constitución, "cada Cámara es juez de las elecciones, derechos y títulos de sus miembros en cuanto a su validez". Sin embargo, ello no ha impedido la existencia de supuestos conflictivos, que han llegado hasta la propia Corte Suprema. Por ejemplo, de acuerdo a la cláusula transitoria cuarta incorporada con la reforma de 1994, "los candidatos a senadores serán propuestos por los partidos políticos o alianza electorales. El cumplimiento de las exigencias legales y estatutarias para ser proclamado candidato será certificado por la justicia Electoral Nacional y comunicado a la

16 Vid., F. P., UBERTONE, "La reforma del Senado. Reflexiones sobre la reforma constitucional de 1994 y los principios del sistema democrático", en Miguel Ángel Ekmekdjian y Raúl Ferreira (coords.), La reforma constitucional de 1994, Depalma, Buenos Aires, 2000.

17 No han faltado las críticas en relación con este artículo. Parte de la doctrina afirma, con buen criterio, que técnicamente hubiera correspondido modificar el texto del artículo 62, en lugar de establecer un mecanismo permanente en una norma transitoria. También se ha discutido si cuando un senador deja vacante su estaño, el senador que lo reemplaza debe ser designado para completar dicho lapso o no. Quienes dan una respuesta negativa sostienen que la Constitución asigna a cada senador un mandato de 6 años no susceptible de reducción. Sin embargo, este no es el criterio adoptado para la Cámara de Diputados. Según el artículo 21 del Reglamento de dicho órgano, "en caso de producirse alguna de las situaciones de vacancia transitoria prevista en el presente artículo, la Cámara podrá disponer la incorporación del suplente, quién cesará en sus funciones cuando se reincorpore el titular". 
Legislatura". La interpretación de este párrafo generó debates en el Senado y llegó incluso a la Corte Suprema de Justicia ${ }^{18}$.

La Constitución nacional prevé dos posibles autoridades para el Senado: el Presidente y el Presidente provisional (Const. Nac., artículo 57; RS, artículo 2, Título III). Según el artículo 57 de la Constitución, y al igual que ocurre en los Estados Unidos, la presidencia del Senado recae en el vice-presidente de la Nación. El sentido de esta opción es, entre otros, tender un puente entre el Poder ejecutivo y el legislativo y conferir tareas al vicepresidente, que de otro modo sería una suerte de "funcionario hibernando" 19 .

En cuanto las mayorías requeridas para aprobar válidamente un asunto, la regla en la Constitución de 1853 era, salvo algunos casos de relevancia institucional, la mayoría absoluta de los miembros presentes (artículo 56) ${ }^{20}$. En caso de enmiendas introducidas por la cámara revisora, esa mayoría podía ampliar$\mathrm{se}^{21}$, y lo mismo ocurriría en caso de la insistencia del Congreso ante un veto del Poder ejecutivo ${ }^{22}$. Tras la reforma de 1994, el sistema queda conformado de la siguiente manera:

18 En el caso "Provincia del Chaco c. Senado de la Nación", de 1998, se discutió la decisión de la Cámara Alta de desechar el título a un senador designado por la Legislatura, perteneciente al "Frente de Todos", por no cumplir con la cláusula mencionada en lo que se refiere al partido o alianza mayoritaria del cuerpo, e incorporar al del Partido Justicialista que la impugna. Ante un pedido de medida cautelar solicitada por el gobernador de Chaco en la que se pedía la suspensión de dicha incorporación, la mayoría de la Corte entendió que la resolución de la cuestión era una facultad privativa del Senado excluida del control jurisdiccional. Este criterio se reiteró en 1999, en el caso "Tomasella Cima" suscitado en la provincia de Corrientes.

19 La segunda autoridad de la Cámara es el Presidente provisional — conocido también como presidente pro tempore - que el mismo Senado debe nombrar, por mayoría absoluta, en caso de ausencia del vice-presidente o cuando éste ejerza las funciones de presidente (artículo 58 de la Constitución y 2 del RS). Igualmente, de acuerdo a la Ley de acefalía, el presidente provisional está llamado a suceder al Presidente de la República en tercer término para el supuesto de renuncia, muerte o incapacidad de aquél y de su sucesor natural, el Vicepresidente de la Nación.

20 Vid., A., ADAGLIO, entre otros, «El Proceso para la formación y sanción de las leyes después de la Reforma de 1994. Su examen a la luz del nuevo Congreso de la Nación y de los Reglamentos de las Cámaras", en Gregorio Badeni (director), Nuevas perspectivas en el derecho constitucional, Villela Editor, Buenos Aires, 2001.

21 Según el artículo 81 de la Constitución, ninguna de las Cámaras puede desechar totalmente un proyecto que hubiera tenido origen en ella y luego hubiese sido adicionado o enmendado por la Cámara revisora. Si el proyecto fuere objeto de adiciones o correcciones por la Cámara revisora, la Cámara de origen podrá por mayoría absoluta de los presentes aprobar el proyecto con las adiciones o correcciones introducidas o insistir en la redacción originaria. A menos que las adiciones o correcciones las haya realizado la Cámara revisora por dos terceras partes de los presentes. En este último caso, el proyecto pasará al Poder Ejecutivo con las adiciones o correcciones de la Cámara revisora, salvo que la Cámara de origen insista en su redacción originaria con el voto de las dos terceras partes de los presentes. En este caso, la Cámara de origen no podrá introducir nuevas adiciones o correcciones a las realizadas por la Cámara revisora.

22 Según el artículo 83, si el Poder Ejecutivo veta un proyecto, éste vuelve a la Cámara de su origen. Ésta lo discute de nuevo, y si lo confirma por mayoría de dos tercios de votos, pasa otra vez a la Cámara de revisión. Si ambas Cámaras lo sancionan por igual mayoría, el proyecto es ley y pasa al Poder Ejecutivo para su promulgación. En cambio, si las Cámaras difieren sobre las objeciones, el proyecto no podrá repetirse en las sesiones de aquel año 
a) El quórum para constituir sesión —y para deliberar - es — como regla- la mayoría absoluta del total de miembros de cada cámara, esto es, al menos más de la mitad (129 diputados sobre 257; 37 senadores sobre 72).

b) Como principio, para aprobar un proyecto de ley se requiere el voto de la mayoría absoluta de los presentes, es decir, al menos la mitad más uno de los legisladores que están sesionando en número suficiente para dar quórum.

c) De manera excepcional, se exige para ciertos supuestos una mayoría agravada que puede consistir en dos tercios del total: 172 diputados y 48 senadores; dos tercios de los presentes; o mayoría absoluta del total: 129 y 37.

Así, además de las excepciones ya previstas en la Constitución de 1853, para declarar la necesidad de reformar la Constitución: dos terceras partes de los miembros del Congreso (artículo 30); para acusar la Cámara de Diputados ante el Senado en caso de juicio político: dos terceras partes de sus miembros presentes (actual artículo 53); para declarar culpable el Senado a los acusados de juicio político: dos tercios de los miembros presentes (actual artículo 59); para corregir o remover al miembro de una de las Cámaras en los supuestos del actual artículo 66: dos tercios de los votos; y para suspender al miembro de una Cámara en caso de querella ante la justicia ordinaria: dos tercios de los votos (actual artículo 70)_; la reforma de 1994 ha incorporado al menos tres tipos de innovaciones:

1) En primer término, el establecimiento de mayorías especiales para sancionar leyes en razón de la materia. Así, la ley reglamentaria de la iniciativa legislativa popular (artículo 39) y de la consulta popular (artículo 40); de la Auditoría General de la Nación (artículo 85) y del trámite y alcances de la intervención del Congreso en el control de los decretos de necesidad y urgencia (artículo 99.3); del Consejo General de la Magistratura (artículo 114); de la ley convenio sobre coparticipación federal de impuestos (artículo 75.2); y de la ley modificatoria del régimen electoral y de partidos políticos (artículo 77).

2) En segundo lugar, la introducción del nuevo criterio de mayoría absoluta sobre la totalidad de los miembros de cada cámara y su aplicación a la totalidad de las leyes mencionadas.

3) En tercer término, la previsión de nuevos supuestos de actos no legislativos para cuya adopción se requiere una mayoría cualificada de $\operatorname{votos}^{23}$.

23 Así, por ejemplo, dos tercios del total de los miembros de cada cámara: para otorgar jerarquía constitucional a tratados internacionales sobre derechos humanos o para denunciar los que gozan de tal estatus (artículo 75.22); dos tercios de los presentes de cada cámara para la designación y remoción del Defensor del Pueblo (artículo 86); dos tercios de los presentes en el Senado para acordar el nombramiento de los magistrados de la Corte Suprema (artículo 99.4); mayoría absoluta del total de miembros de cada cámara para aprobar o denunciar los Tratados de integración con otros países de América Latina indicados en el artículo 75. 24; para delegar en comisiones la aprobación en particular de proyectos de ley (artículo 79) y para remover al jefe de Gabinete (artículo 101); mayoría absoluta del total de los miembros de cualquiera de las cámaras para interpelar al Jefe de Gabinete a efectos de una moción de censura (artículo 101). 
En principio, las sesiones del Senado son públicas. La publicidad de la sesiones de la comisión de acuerdos a los magistrados del Poder judicial, así como a los altos cargos administrativos y militares, es un cambio muy importante operado a partir de 1994. Estas sesiones, que habían sido secretas hasta entonces, se convirtieron en audiencia pública con la reforma del Reglamento de 2003 (RS, artículos 22 bis y ter, 123 bis, y ss.). El nuevo método, que prevé la utilización de Internet como instrumento de información pública, se usó por primera vez para prestar acuerdo al juez de la Corte Suprema Raúl E. Zaffaroni. Para ello fueron útiles los elementos recogidos, en apoyo o cuestionando al postulante, por el trámite previsto en el reciente Decreto presidencial n. ${ }^{\circ} 222$, de 2003.

El Congreso argentino desempeña varias tareas: sanciona leyes, formula declaraciones y resoluciones, impone controles, etcétera. En la mayoría de ellas, el papel atribuido al Senado es, al menos en el plano formal, tan o más determinante que el reconocido a la Cámara de Diputados.

\section{A) Funciones de ReVisión CONSTitucional}

El artículo 30 de la Constitución prevé la posibilidad de reformas totales y parciales de su texto. El poder de convocatoria se encomienda a las dos cámaras del Congreso, diputados y senadores, que deben aprobar la necesidad de reforma con el voto de las dos terceras partes, al menos, de sus miembros. El poder efectivo de reforma, por su parte, se atribuye a una Convención o Asamblea constituyente elegida a tales efectos.

En la práctica constitucional, la decisión de convocatoria de la reforma se ha adoptado mediante ley y la mayoría exigida ha sido la de los miembros presentes en la sesión de la Cámara respectiva, una vez conseguido el quórum para funcionar. Sin embargo, la experiencia ofrece algunos casos singulares. Cuando a fines de 1993 se declaró la necesidad de reformar la Constitución por ley 24.309, el proyecto que había aprobado la Cámara de Diputados, como cámara revisora, establecía un plazo de cuatro años para el mandato de los senadores. El precepto en cuestión fue enmendado por la Cámara alta, que aceptó la reducción del mandato pero sin establecer plazo alguno. La ley, con esta versión, fue enviada al Poder Ejecutivo, que la promulgó sin vetarlo. De ese modo, se obvió el requisito constitucional de que el Senado devolviera a la Cámara de diputados el texto sancionado con la modificación señalada.

\section{B) Funciones legisLativas}

La denominación "Poder Legislativo" que la Constitución da al Congreso en su artículo 44 refleja la función central, aunque no exclusiva, encomendada a las Cámaras en el sistema de reparto de poderes. La regulación del proceso legislativo formal y de su alcance material ha merecido una consideración bas- 
tante larga, compleja e intricada por parte de la Constitución a lo largo de los diferentes capítulos de la Sección I del Título I.

El artículo 77 de la Constitución estipula que «Las leyes pueden tener principio en cualquiera de las Cámaras del Congreso, por proyectos presentados por sus miembros o por el Poder Ejecutivo, salvo las excepciones que establece esta Constitución". Concretamente, pueden introducir proyectos desde un punto de vista jurídico el Presidente de la Nación ${ }^{24}$, uno o varios miembros del Senado, uno o varios legisladores de la Cámara de Diputados y, tras la incorporación en 1994 de la iniciativa legislativa popular (artículo 39 Const. Nac.), un número de ciudadanos que represente como máximo el 3\% del padrón electoral ${ }^{25}$.

En cuanto a la cámara de origen, pueden serlo indistintamente la Cámara de Diputados o el Senado en un amplio número de materias atribuidas al Congreso en el artículo $75^{26}$. La principal excepción a este principio venía dada, en la Constitución de 1853, por el establecimiento de la Cámara de Diputados como cámara de origen en materia de "contribuciones" y "reclutamiento de tropas» (actual artículo 52, ex 44) ${ }^{27}$. La reforma constitucional de 1994 ha introducido dos cambios importantes en esta cuestión.

Por un lado, ha ampliado las materias cuyo tratamiento inicial corresponde exclusivamente a la Cámara de Diputados. Así, a la correspondiente a contribuciones y reclutamiento de tropas agregó los proyectos promovidos mediante la iniciativa legislativa popular (artículo 39) y la ley de convocatoria para someter a consulta popular un proyecto de ley (artículo 40). Sin embargo, también ha convertido al Senado en cámara de origen en dos supuestos: la ley convenio entre la Nación y las provincias sobre el régimen de coparticipación federal de impuestos (artículo 75.2) — que aunque en el plano formal limita la primacía de la Cámara de Diputados en materia tributaria, no ha sido dictada aún-y las leyes "para proveer al crecimiento armónico de la Nación y al poblamiento de su territorio" y para "promover políticas diferenciadas que tiendan a equilibrar el desigual desarrollo relativo de provincias y regiones" (artículo 75. 19).

24 Con el obligatorio refrendo, según el artículo 100 de la Constitución, del jefe de Gabinete y de los ministros del ramo.

25 La ley 24.747 de reglamentación del derecho de iniciativa legislativa popular estableció en su artículo 4 que éste arequiere la firma de un número de ciudadanos no inferior al uno y medio por ciento (1.5\%) del padrón electoral utilizado para la última elección de diputados nacionales, y deberá representar por lo menos a 6 distritos electorales.

26 Entre otras, arreglar el pago de la deuda interior y exterior de la Nación (inc. 7); dictar los códigos Civil, Comercial, Penal, de Minería y del Trabajo y la Seguridad Social, en cuerpos unificados o separados (inc. 12); reglar el comercio con las naciones extranjeras, y de las provincias entre sí (inc. 13); arreglar definitivamente los límites del territorio (inc. 15); proveer a la seguridad de las fronteras (inc. 16); aprobar o desechar tratados con concluidos con las demás naciones y organizaciones internacionales (inc. 22), legislar y promover medidas de acción positiva (inc. 23); autorizar al poder ejecutivo para declarar la guerra o hacer la paz (inc. 25); disponer la intervención federal a una provincia (inc. 31), etc.

27 En la práctica constitucional, la expresión "contribuciones" ha sido interpretada en un sentido amplio, restringiendo notablemente la iniciativa tributaria del Senado 
Desde el punto de vista de las mayorías exigidas para plantear y levantar enmiendas, la reforma de 1994 ha intentado simplificar el ya de por sí complejo proceso legislativo, reforzando el papel de la cámara de origen frente al de la eventual cámara revisora. Como salvo en los casos arriba apuntados, un proyecto puede iniciarse tanto en el Senado como en la Cámara de Diputados, lo más frecuente es que el Poder ejecutivo o los legisladores del partido que gobierna presenten sus proyectos en la Cámara en la que tengan mayor peso político.

\section{C) Funciones De CONTROL}

El sistema de gobierno argentino ha sido, desde la aprobación de la Constitución de 1853, fuertemente presidencialista. Esa circunstancia, favorecida por circunstancias históricas, económicas y sociales, ha dificultado el ejercicio de controles adecuados por parte del Congreso y ha favorecido, más bien, la dependencia del Poder legislativo del Poder ejecutivo de turno. A pesar de iniciarse, paradójicamente, para impulsar la reelección de un presidente - Carlos Menem - uno de los objetivos declarados - aunque no cumplidos- de la reforma de 1994 fue moderar esa herencia hiperpresidencialista.

Para comenzar, entre las subfunciones electivas del Congreso se cuenta la de tomar juramento de posesión de cargo al presidente y vicepresidente (artículo 93 de la Const. Nac.) Asimismo, el artículo 88 estipula que en caso de destitución, muerte dimisión o inhabilidad del presidente y vicepresidente de la Nación (doble acefalía), el Congreso determinará que funcionario público ha de desempeñar la Presidencia, hasta que haya cesado la causa de inhabilidad o un nuevo presidente sea electo.

En cuanto a las subfunciones integrativas del Congreso, el artículo 76 prohíbe en principio la delegación legislativa en el Poder Ejecutivo, auque la admite en ciertas materias de administración o de emergencia pública, con plazo fijado para su ejercicio y dentro de las bases de la delegación que las Cámaras del Congreso establezcan.

El artículo 99 de la Constitución, por su parte, establece que el Poder Ejecutivo no podrá en ningún caso bajo pena de nulidad absoluta e insanable, emitir disposiciones de carácter legislativo". Sin embargo, según el mismo precepto, en "circunstancias excepcionales" y en materias determinadas, podrá dictar decretos por razones de necesidad y urgencia, los que serán decididos en acuerdo general de ministros que deberán refrendarlos, conjuntamente con el jefe de gabinete de ministros. La Constitución también establece que dentro de diez días el jefe de gabinete de ministros deberá someter la medida a control de una Comisión Bicameral Permanente, "cuya composición deberá respetar la proporción de las representaciones políticas de cada Cámara". Sin embargo, la ley especial que por mayoría absoluta de la totalidad de los miembros de cada Cámara deberá regular el trámite y los alcances de la intervención del Congreso aún no ha sido sancionada (artículo 99.3). 
La subfunción integrativa del Congreso se manifiesta también a través de una serie de autorizaciones, aprobaciones y permisos al Poder ejecutivo. Así, el artículo 75.25 exige la autorización del Congreso para declarar la guerra o hacer la paz. El 61, por su parte, exige la autorización del Senado para declarar el estado de sitio en caso de ataque exterior. El 75.28, a su vez, requiere el permiso del Congreso para la introducción de tropas extranjeras al territorio de la $\mathrm{Na}$ ción.

Una de las novedades de la reforma constitucional de 1994, introducida con el objetivo de atenuar el hiperpresidencialismo, fue la de atribuir parte de la tarea que recae sobre el Presidente de la Nación — sobre todo en materia administrativa - a un Jefe de Gabinete de Ministros ${ }^{28}$. Según los artículos 100 y 101 de la Constitución, el Jefe de Gabinete es responsable ante el Congreso de la Nación y debe concurrir alternativamente a cada una de sus Cámaras al menos una vez por mes, para informar de la marcha del gobierno. Los artículos 214 y 215 del Reglamento del Senado, por su parte, establecen un orden de la palabra en el caso de que los ministros o el jefe de gabinete concurran, así como las reglas que rigen las comparecencias de este último.

Aunque en los reglamentos de las Cámaras y en el lenguaje de los congresistas se habla de interpelación, estas subfunciones cognoscitivas y de inspección difieren claramente de la existente en sistemas parlamentarios ${ }^{29}$. De hecho, la concurrencia de los ministros al plenario de las cámaras no ha sido frecuente en la práctica constitucional de los últimos 50 años. Los ministros asisten pocas veces invitados a las comisiones y casi nunca al plenario de las cámaras. Incluso si se llega a este último supuesto, no se sigue el trámite previsto en el reglamento para las interpelaciones.

Por otra parte, el voto de censura previsto en el artículo 101 para el jefe de gabinete de ministros, no solamente no ha sido utilizado desde que fuera incorporado en la Constitución en la reforma de 1994, sino que los reglamentos de ambas cámaras no lo han desarrollado ${ }^{30}$.

Como mecanismos auxiliares del Congreso en el control del gobierno, la reforma de 1994 ha introducido la figura de la Auditoría General de la Nación, elegida por el propio Congreso y encargada del control externo de las finanzas y el patrimonio del sector público (artículo 85); y del Defensor del

28 Este funcionario - más cercano al modelo establecido en la Constitución del Perú de 1978 que, por ejemplo, al contemplado en la Constitución portuguesa- se ocuparía entre otras cuestiones de los nombramientos en la administración pública, de la elaboración y sometimiento al Congreso de las leyes de ministerio y presupuesto, o de la recaudación impositiva y la ejecución del presupuesto.

29 Para comenzar, porque no hay voto de censura. Los pedidos de informes escritos que hacen las cámaras al Poder Ejecutivo, por su parte, no siempre son respondidos. Con el objeto de paliar esa situación, el Congreso sancionó la ley 24.157, pero ésta fue vetada por el entonces Presidente Menem mediante el Decreto 1955/92.

$30 \mathrm{El}$ jefe de gabinete — establece el artículo 101— puede ser interpelado a los efectos del tratamiento de una moción de censura, por el voto de la mayoría absoluta de la totalidad de los miembros de cualquiera de las Cámaras, y ser removido por el voto de la mayoría absoluta de los miembros de cada una de las Cámaras. 
Pueblo, también elegido, como se verá, por las cámaras del Congreso, y encargado de proteger los derechos humanos frente a la Administración y de supervisar su actuación (artículo 86).

\section{D) FunCIONES DE NOMINACIÓN Y ELECCIÓN}

El Senado presta acuerdo a la designación que hace el Presidente de la Nación de los Magistrados de la Corte Suprema y de los demás tribunales federales inferiores; de los Ministros Plenipotenciarios y Encargados de Negocios, y la provisión de los empleos militares de oficiales superiores de ejército y armada; y por sí sólo en el campo de batalla (artículo 99. 4, 7 y 13 Const. Nac.).

En la última reforma constitucional se estableció que el acuerdo del Senado para la designación de jueces de la Corte Suprema necesitaba de dos tercios de los miembros presentes, y respecto de los demás jueces de tribunales federales inferiores el Presidente los nombra en base a una propuesta vinculante en terna del Consejo de la Magistratura, en sesión pública, y donde se tendrá en cuenta la idoneidad de los candidatos ${ }^{31}$.

El Presidente, además, "puede llenar vacantes de los empleos, que requieran el acuerdo del Senado, y que ocurran durante su receso, por medio de nombramientos en comisión que expirarán al fin de la próxima Legislatura" (artículo 99. 19 Const. Nac.) Los acuerdos deben prestarse para la designación de un cargo determinado y concreto, por lo que cualquier traslado, cambio de grado o de sede necesita nueva designación y acuerdo del Senado. La publicidad de la sesiones de la comisión de acuerdos, como ya se ha dicho antes, es un cambio muy importante introducido a partir de 1994 y con la reforma del Reglamento del Senado de 2003.

Según lo dispuesto en la Ley 24.1444, el Senado tienen un papel importante a la hora de dar el acuerdo al presidente, vicepresidente y directores del Banco Central designados por el Poder Ejecutivo. La ley 24.946, por su parte, exige acuerdo del Senado para designar al Procurador General y al Defensor General de la Nación, cabezas del Ministerio Público (artículo 120 de la Constitución). Hay cargos, por otro lado, cuya designación corresponden a ambas cámaras, como el de los seis auditores generales que componen la Auditoría General de la Nación ${ }^{32}$, el De-

31 El párrafo 4 del artículo 99 establece que «un nuevo nombramiento será necesario, precedido de igual acuerdo, para mantener en sus cargos a los magistrados, una vez que cumplan la edad de setenta y cinco años. Todos los nombramientos de magistrados cuya edad sea la indicada o mayor se harán por cinco años, y podrán ser repetidos indefinidamente, por el mismo trámite" Este precepto fue declarado nulo por el discutido fallo de la Corte Suprema en el caso "Fayt, Santiago", (Fallos 322:1616) de 1999.

32 Según el artículo 112 de la ley 24.156, "serán designados por resolución de las dos Cámaras del Congreso Nacional, correspondiendo la designación de tres a la Cámara de Senadores y tres a la Cámara de Diputados, observando la composición de cada Cámara”. El artículo 123 agrega: «El séptimo Auditor General será designado por resolución conjunta de los presidentes de las Cámaras de Senadores y de Diputados y será presidente del ente.. El artículo 85 de la Constitución dispone además que "El presidente del organismo será designado a propuesta del partido político de oposición con mayor número de legisladores en el Congreso". 
fensor del Pueblo ${ }^{33}$ o los 8 legisladores que componen el Consejo de la Magistratura (artículo 2.3 de la ley 24.937, modificada por la 24.939). El Jurado de Enjuiciamiento, que está integrado por nueve miembros, tiene tres legisladores, dos provenientes del Senado (uno por la mayoría y otro por la primera minoría) y un legislador perteneciente a la Cámara de Diputados de la Nación, elegido por mayoría de votos" (artículo 22, inciso 2 de las misma ley).

\section{E) FunCiOnes JURISDiCCIONALES (O POLÍTICO-JURISDiCCIONALES)}

Según el artículo 59 de la Constitución, corresponde al Senado «juzgar en juicio político a los acusados por la Cámara de Diputados, debiendo sus miembros prestar juramento para este acto. Cuando el acusado sea el presidente de la Nación, el senado será presidido por el presidente de la Corte Suprema. Ninguno será declarado culpable sino a mayoría de los dos tercios de los miembros presentes". El artículo 60, por sumarte, establece que "Su fallo no tendrá más efecto que destituir al acusado, y aún declararle incapaz de ocupar ningún empleo de honor, de confianza o a sueldo en la Nación. Pero la parte condenada quedará, no obstante, sujeta a acusación, juicio y castigo conforme a las leyes ante los tribunales ordinarios".

El procedimiento legislativo está regulado por el Reglamento interno de la Comisión de Juicio Político de la Cámara de Diputados y por el Reglamento del Senado constituido en tribunal para el caso de juicio político. Aunque la decisión del Senado no es en principio recurrible —así lo especifica el artículo 115 de la Constitución a propósito del fallo dictado por el Jurado de Enjuiciamiento de Magistrados - la jurisprudencia de la Corte Suprema admite la revisión si se vulnera la garantía de la defensa o la del debido proceso legal adjetivo $^{34}$.

\section{F) FunCIONES DE AUTORIZACIÓN}

El cuadro de funciones senatoriales puede completarse con aquellos supuestos en los que la autorización del Congreso es necesaria para el ejercicio de ciertas competencias provinciales. Así, por ejemplo, el artículo 124 prevé que las provincias puedan crear regiones para el desarrollo económico y social, es-

33 La ley 24.284 estipula que una comisión bicameral permanente de siete senadores y siete diputados, convocada por el presidente del Senado, propondrá a las cámaras de uno a tres candidatos los que se someterán a votación dentro de los treinta días siguientes al pronunciamiento de la comisión y será elegido por ambas Cámaras el que obtenga dos tercios de los votos de los presentes (artículo 2 de la ley, artículo 86 de la Const. Nac.) El cese del Defensor del Pueblo, por su parte, "Se decidirá por el voto de los dos tercios de los miembros presentes de ambas cámaras, previo debate y audiencia del interesado" (artículo 11).

34 Así, por ejemplo, en el caso "Nicosia", Fallos 316: 2940. 
tablecer órganos con facultades para el cumplimiento de sus fines o celebrar convenios internacionales en tanto no sean incompatibles con la política exterior de la Nación y no afecten las facultades delegadas al Gobierno federal o el crédito público de la Nación. En esos casos, será preceptivo dar conocimiento al Congreso. En sentido similar, el artículo 125 de la Constitución contempla la posibilidad de que las provincias celebren tratados parciales para fines de administración de justicia, de intereses económicos y trabajos de utilidad común, con conocimiento del Congreso.

El artículo 126, por fin, impide a las provincias celebrar tratados parciales de carácter político; expedir leyes sobre comercio, o navegación interior o exterior; establecer aduanas provinciales; acuñar moneda; o establecer bancos con facultades de emitir billetes, sin autorización del Congreso federal. Tampoco les permite dictar los códigos Civil, Comercial, Penal y de Minería, después que el Congreso los haya sancionado.

\section{EL SENADO EN LAS ENTIDADES FEDERADAS}

La Constitución nacional prevé que cada provincia dicte una Constitución bajo el sistema representativo republicano, de acuerdo con los principios, declaraciones y garantías de la Constitución nacional (artículos 5 y 123 Const. $\mathrm{Nac}$.). Eso supone la posibilidad de que regulen sus propias instituciones y elijan a sus gobernadores, legisladores y funcionarios, sin intervención del Gobierno federal (Const. Nac., artículo 122).

La Corte Suprema, por su parte, ha afirmado que no se puede exigir que las constituciones provinciales sean "una copia literal o mecánica" o "una reproducción más o menos exacta e igual" de la Constitución nacional (Fallos, $311: 460)^{35}$. En lo que concierne a la organización territorial del poder, las 23 provincias hoy existentes asumen alguna variante de descentralización administrativa, por ejemplo, mediante un reconocimiento explícito de la autonomía municipal. De ellas, por su parte, 15 consagran un sistema legislativo unicameral, a veces como producto de una decisión "originaria", a veces como producto de enmiendas recientes ${ }^{36}$.

Las 8 provincias restantes - Buenos Aires, Catamarca, Corrientes, Entre Ríos, Mendoza, Salta, San Luis y Santa Fe- mantienen en sus Constituciones un Poder legislativo bicameral con sus particularidades pero naturalmente influido también por la Constitución estatal. En la totalidad de los casos, por ejemplo,

35 Vid. P. J. FRÍAS,, Introducción al Derecho Público provincial, Desalma, Buenos Aires, 1980.

36 Así, las constituciones de Córdoba (art. 77), Chaco (art. 96), Chubut (art. 124), Formosa (art. 101), Jujuy (art. 103), La Pampa (art. 53), La Rioja (art. 84), Misiones (art. 82), Neuquén (art. 71), Río Negro (art. 122), San Juan (art. 131), Santa Cruz (art. 85), Santiago del Estero (art. 115), Tierra del Fuego (art. 89), Tucumán (art. 39). También se decanta por un sistema unicameral la Constitución de la ciudad autónoma de Buenos Aires (art. 68). 
los senadores son escogidos de manera directa por los propios electores ${ }^{37}$. Su número, por otro lado, puede establecerse de manera fija o variar de acuerdo a criterios demográficos, al igual que el mandato de los senadores. Muchas otras cuestiones vinculadas a los requisitos establecidos para ser senador, al proceso de elaboración de las leyes, al control del ejecutivo o al nombramiento de otros cargos, se regula en las Constituciones provinciales bicamerales de manera similar a lo que ocurre con la Constitución estatal.

\section{EL SENADO ARGENTINO EN EL SISTEMA CONSTITUCIONAL Y SUS PERSPECTIVAS DE FUTURO}

Como puede advertirse, desde un punto de vista formal el Senado ocupa un lugar relevante dentro el sistema constitucional. Sus facultades legislativas y de control son casi tan importantes como las de la Cámara de Diputados. Además, es una suerte de "Consejo de Estado", ya que presta acuerdo para la designación de funcionarios superiores del gobierno federal y destituye a los que ocupan los cargos de mayor relevancia, para lo cual actúa como tribunal del juicio político, en caso de mal desempeño, delitos en el ejercicio de sus funciones o crímenes comunes.

A pesar de todo ello, el Senado argentino no ha podido evitar el sostenido proceso de "desfederalización" de la forma de Estado ni la "Sucursalización" de las provincias, que ha conducido a su creciente pérdida de autonomía. Las razones de este déficit deben buscarse no sólo en elementos internos de diseño institucional, sino en un sinúmero de factores políticos, económicos y culturales que han impedido el desarrollo de un Estado social, democrático y de derecho en la Argentina y que han contribuido a la consagración, en último término, de un auténtico "unitarismo solapado" 38 .

Parte de la doctrina, por ejemplo, considera que la reforma constitucional de 1994 reforzó el perfil federal del Senado y su función como órgano de control. Sin embargo, como se ha visto a lo largo de este trabajo, tanto por el desarrollo efectivo de la institución como por los sonados casos de corrupción protagonizados entre 2001 y 2003, nada autoriza una conclusión en exceso positiva.

La inclusión del tercer senador no ha resuelto los problemas de fondo, aumentando en cambio el aparato burocrático de la Cámara y duplicando, en al-

37 En ese sentido, por ejemplo, las Constituciones de Buenos Aires, art. 68; Catamarca, art. 71; Corrientes, art. 48; Entre Ríos, art. 60; Mendoza, art. 64; Salta, art. 100; San Luis, art. 109; Santa Fe, art. 36 .

38 Vid., entre otros, A. DALLA VÍA, "Actualidad del federalismo argentino", en José María Serna de la Garza (coord.), Federalismo y regionalismo. Memoria del VII Congreso Iberoamericano de Derecho Constitucional, Instituto de Investigaciones Jurídicas, México, 2002; J. GENTILE, "El Senado: ¿es una Cámara federal?", en Walter F. CARNOTA (ed.), Derecho federal. Sus implicancias prácticas, op. cit.; A. Hernández, "La ordenación de las instituciones y los poderes en los Estados compuestos", en Enric Argullol (director), Federalismo y autonomía, Ariel, Barcelona, 2004, pp. 419 y ss. 
gunos aspectos, ciertas lógicas de funcionamiento de la Cámara de Diputados. El dictado de decretos por razones de necesidad y urgencia (art. 99. 3 Const. Nac.) y la legislación delegada (art. 76 Const. Nac), antes y después de 1994, han traído mayor concentración de funciones en el Poder ejecutivo. Ninguno de estos instrumentos normativos ha sido reglamentado de manera adecuada, ni se ha creado la Comisión Bicameral Permanente prevista para su control en los artículos 99.3 y 100. 12 y 13 de la Constitución, así como en la Cláusula Transitoria Octava. La introducción del jefe de gabinete - designado por primera vez en 1995- tampoco ha servido en la práctica para atenuar un presidencialismo de fuertes connotaciones plebiscitarias.

El Estado federal y las provincias tienen competencias concurrentes en materia de impuestos directos. En la práctica, sin embargo, el Estado federal ha legislado y recolectado los tributos de mayor potencial recaudatorio, lo que ha producido un aumento de los desequilibrios en la asignación del gasto. Aunque la reforma de 1994 constitucionalizó la coparticipación federal, nada asegura que este mecanismo, nacido ante las insuficiencias del sistema de atribución de competencias en materia fiscal, vaya a dejar de reproducir las patologías que generó en el pasado y que contribuyeron a afianzar la dependencia de las provincias del poder central. La reforma también otorgó jerarquía constitucional a los fondos de asignación específica y a un organismo fiscal federal. Sin embargo, ni la nueva ley de coparticipación — cuyo impulso debería plantearse en el Senado como Cámara de origen (art. 75.2 Const. Nac.) - ni el mencionado organismo, se pusieron en marcha antes de la finalización de 1996, como preveía la Cláusula Transitoria Sexta.

Por otro lado, a pesar de la bondad de algunas previsiones constitucionales, ha seguido agudizándose la concentración de recursos económicos, sobre todo como consecuencia de la gran cantidad de servicios, gastos y funciones que el Estado federal transfirió a las provincias en los últimos años sin la contrapartida presupuestaria. La autonomía municipal ha tenido un cierto desarrollo en algunas provincias, aunque las restricciones al gasto público han limitado progresos mayores y, en algunos casos, han propiciado retrocesos. El establecimiento de regiones para el desarrollo económico social (artículo 124 Const. Nac.) tampoco ha tenido el desarrollo esperado. Por el contrario, para paliar los daños causados por la grave crisis, las provincias han recurrido al endeudamiento y al déficit fiscal. La quiebra de la disciplina fiscal, la dependencia de las provincias de los recursos federales, que el Gobierno federal suele manejar a discreción, y las exigencias del clientelismo político, han desordenado aún más el gasto público y la certidumbre de los ingresos que le corresponden a cada jurisdicción. Esto ha contribuido a la celebración de "pactos" y "guerras fiscales" entre las provincias, así como a la creación de "ligas de gobernadores" que se atribuyen funciones propias del Senado.

En un contexto así, el Senado argentino se encuentra en una situación especialmente crítica. Aunque no han faltado propuestas concretas de reforma para la Cámara - desde las que propugnan un regreso a los 2 senadores por provincia hasta las que insisten en la necesidad de trasladar la capital del Estado 
a una provincia del interior y, con ella, las Cámaras del Congreso- lo cierto es que buena parte de la doctrina coincide en que el futuro del Senado no se juega ni sólo ni tanto en eventuales innovaciones de tipo normativo.

En buena medida, la reactivación republicana de la Cámara Alta tiene que ver con el cumplimento de los elementos más avanzados del programa federalista, social y democrático incorporado por la Constitución tras de la reforma de 1994. Desde la profundización de la autonomía regional, provincial y municipal, hasta la limitación del presidencialismo y la asunción por parte del Senado de su papel constitucional en cuestiones como el impulso de un régimen de coparticipación fiscal solidario o de políticas de desarrollo y de reequilibrio inter-territorial.

También se plantea, de manera previa o simultánea, la necesidad de incidir en el "entorno externo" que atenaza el desarrollo del sistema institucional argentino en su conjunto: plantear una salida valiente al problema de la deuda externa, que posibilite ampliar el margen de lo "políticamente posible" desde el punto de vista social; revertir la ola privatizadora de las últimas décadas y dar paso a políticas redistributivas y de protección de los servicios públicos que mejoren la posición de los ciudadanos y las provincias en situación de mayor universalidad, etc.

En los últimos años, algunas de estas cuestiones han comenzado, de manera tímida, a incorporarse a la agenda política y social del país. En todo caso, la fisonomía que vaya adquirir el régimen federal, y con él, el propio Senado, dependerá en gran medida de la voluntad política de los propios ciudadanos, movimientos sociales y partidos, así como de su capacidad de asumir e impulsar las reformas necesarias. También aquí, la "lucha por el derecho" y el impulso de una nueva "cultura federal" son un requisito indispensable para avanzar en una organización territorial del poder más solidaria, transparente y democrática.

ABSTRACT. The debate on political decentralization in Argentina finds its reasons in the Federal Constitution drafted in 1853. From its first reform in 1860 to the last one dating back to 1994, this is the texts still in force today. The reform of 1994 has introduced some relevant innovations in the Senate's configuration. In practice, however, it faces a critical situation. On the one hand, the Senate is a fundamental institution of the political system and has a decisive role as a legislative, control and advisory body. It is also the representative House of the provincial autonomies and of the city of Buenos Aires. On the other hand, the possibility that the Senate can be transformed into the real fuel of a new "federal culture" seems nowadays still not in sight. In addition to institutional reforms, the Senate's final features mainly depend on the political goodwill of the citizens, social movements and political parties. Even in this case, "the struggle for the law" is the essential precondition for a federal organization based on the values of solidarity, transparency and territorial democracy. 